Article

\title{
Implementation of Enterprise Risk Management (ERM) Framework in Enhancing Business Performances in Oil and Gas Sector
}

\author{
Sanmugam Annamalah ${ }^{1, *}$ (1), Murali Raman ${ }^{2}$, Govindan Marthandan ${ }^{2}$ and \\ Aravindan Kalisri Logeswaran ${ }^{2}$ \\ 1 Faculty of Business, SEGi University College, Kuala Lumpur, Wilayah Persekutuan 50100, Malaysia \\ 2 Faculty of Management, Multimedia University, Cyberjaya 63100, Malaysia; \\ murali.raman@mmu.edu.my (M.R.); marthandan@mmu.edu.my (G.M.); aravindan@mmu.edu.my (A.K.L.) \\ * Correspondence: sanmugam_1@yahoo.com or sanmugam@segi.edu.my; Tel.: +60-125-662-562
}

Received: 2 November 2017; Accepted: 29 December 2017; Published: 15 January 2018

\begin{abstract}
This study empirically investigated the ERM Implementation model and proposed framework to identify and manage risks in Oil and Gas Sector in Malaysia. The study examined the role of ERM framework implementation in improving business performance by utilizing Economic Value Added as a measurement tool. The study also provides insights to the Oil and Gas Sector to gain higher profit returns, reduce cost of capital, and improve shareholders value. Moreover, it contributes significantly in the field of Enterprise risk management in Malaysia. The identification and management of risk is significant to organizations in managing risks efficiently. Expectations of stakeholders of the organization are high from executives and board of directors in managing the risk effectively. Linear regression analysis is utilized in analyzing the data obtained from the data collection performed for this paper. Purposive sampling has been employed in order to select the firms that are operating in Malaysian oil and gas sector. Primary data has been utilized to collect data with the help of structured questions and interview techniques that involve semi structured questions. The results of the regression analysis conducted for in this study suggested that a significant and positive relationship between Enterprise Risk Management with operational risk; market risk; political risk; health, safety and environmental risk; and, also business performance.
\end{abstract}

Keywords: enterprise risk management; economic value added; oil; gas; Malaysia

JEL Classification: G32

\section{Introduction}

Due to the technology advancement in 21st century, many companies faced myriad of risks, such as internet, complex financial instruments, global competition, deregulations, downsizing, and the consumer demands are some of the major risk factors in an organizational environment (Shenkir and Walker 2006). Malaysia remains one of South East Asia's most dynamic producer of oil and gas, and it is considered as the keystone in the Malaysian economy. The exploration of Petroleum products started in Sarawak with the start of 20th century, in Sarawak, in 1909, Oil was for the first time was discovered and later in 1910 the production of oil was carried out Sarawak. In the whole world, Malaysia is among the countries that 25th biggest reserved of Oil and 14th biggest reserves of Gas. Based on Jin et al. (2013), the Oil \& Gas (O\&G) sector contributes about $40 \%$ of the nation's total revenue. The government of Malaysia collected direct and indirect taxes from $O \& G$, amounting to RM 34.4 billion in 2012. In 2015, the company registered RM329 billion in revenues, and therefore, O\&G is considered as one of the main pillars of the Malaysia's economy due to the contribution of O\&G industry to Malaysian economy. 
Many forms of risks are involved in the field of $O \& G$ and most of them are exposed to risks, such as government policies, environmental incidents, operational, survival circumstances, and market threats. These risks should be managed in an effective manner or else it will lead to a huge effect on firm's value (Nguyen et al. 2007). Risks that occur frequently in O\&G industries are political risk, environmental risk, operational risk, market risk; climate change risk, financial risk; regulatory risk; and, strategic risk, and these risks are increasingly evident, particularly during and after financial crises (Jalal-Karim 2013; Othman and Ameer 2008). Financial rises 1997-1998 have badly affected Malaysian companies and it is mainly due to the poor risk management (Yazid and Muda 2006). As the crisis resulted in currency devaluation throughout the region (Yazid 2001), many companies suffered loss due to these crises, for instance, Tenaga Nasional Bhd (TNB), the main energy provider in Malaysia, suffered a loss of RM 2.47 billion, Telekom Malaysia ${ }^{\mathrm{TM}}$, a telecommunications provider, suffered a loss of RM 158 billion (Yazid 2001).

Malaysia Airline System (MAS) suffered a loss of RM 300 to 400 million (Financial Express 1998). There have been impressive changes in the role of risk management as most corporations responded by shifting towards strategic risk management in their operations (Nocco and Stulz 2006). Most of the organizations responded by implementing enterprise risk management (ERM) to manage the risk in accordance with the directions of well-known corporations of United States (US), such as General Electric (GE), Wal-Mart, Bank of America, and IBM, whereby they have implemented ERM effectively in managing their risks (Drew et al. 2005). ERM evaluates and improves the effectiveness of risk management, in which it provides assurance to stakeholders the capabilities of management in governing the risks (Beasley et al. 2006). ERM has been recognized as one of the most significant tools in managing risks in businesses and to ensure that mishaps are prevented to the best possibility, which is in accordance to organizations objectives. Researchers have recommended various frameworks like COSO's Enterprise Risk Management-Integrated Framework, Traditional risk management framework, Arthur Anderson Business risk management process etc., but though they are difference in names, industries, areas, and regions, but they all share a common theme that is identification, prioritization, measurement, and treatment of risk. However, the ERM framework provides companies with key principles and concepts and clear direction, as well as guidance to solve specific risk (Jalal-Karim 2013).

\section{Literature Review}

ERM implementation framework that has been adopted encompasses three dimensions (i.e., structure, governance, and process), extended to seven areas (Lai 2012). These fourteen areas are operationalized with implementation of 14 elements. The focus of the research involves two areas, i.e., ERM definition, and performance measurement, and these two areas are operationalized by four implementation elements. The governance dimension covers two areas (i.e., information and roles, and compliance), with four implementation elements. The process dimension includes three areas (i.e., integration of business strategy and objectives, risk identification and response, and risk quantification), with six implementation elements. According to Lai (2012), the ERM framework consists fourteen elements, which are considered as significant for an effective and efficient management of risks faced by firms.

The proposed model is strategic as it covers all idiosyncratic risk. Hence, the use of ERM Implementation Framework is to identify the various types of risk that are involved in the Oil and Gas Sector, and to examine the effects of implementing the framework to manage the identified risks. In addition, it investigates the impact of the framework on business performances (Richard et al. 2009).

Hybrid measuring techniques is undertaken to overcome the accounting and market weaknesses (Richard et al. 2009). Three hybrid measures that exist are the Tobin's q, the Altman's Z score, and Economic Value Added (EVA). This model that was proposed in this study was economic value added (EVA). EVA is referred to as economic profit as it attempts to capture the true economic profit of a company in short and long term performances. EVA is developed and trademarked by Stern Stewart \& Co., as a measurement tool in 1989. EVA shows overall operating profit inclusive of taxes (NOPAT), 
minus weighted average cost of capital multiply by total capital Stewart (1990). Mathematically, it can be given as study utilized model:

$$
\mathrm{EVA}=\mathrm{NOPAT}-(\mathrm{TC} \times \text { Cost of capital })
$$

where NOPAT - operating profit inclusive of taxes, TC-Total capital.

According to EVA a company is "create value":

If EVA > 0, then organization utilizes their own capital in an efficient, this helps to increase the company's value.

If $\mathrm{EVA}=0$, then the organization gains and capital cost are same as the time of initial investment. If EVA $<0$, then the organization and decrease in company's value.

EVA is a useful to measure performances, because it helps to find out the net profit adjustment by cost of capital (Black 1998). On the other hand, ERM is useful because it aims to minimize the cost of capital in order to enhance performances. ERM program implemented to reduce the cost of capital and to improve the business performance (Lai and Samad 2010). EVA measures the performance of financial status of a company and highlights the precise profit of that organization (Stewart 1990).

For the success of almost every organization, proper risk management in all perspectives is essential, especially in the global business era. ERM is a comparatively new model and yet to be fully implemented in most of organizations. Despite of recognizing its importance, many industries are still proceeding to implement inaccurate risk management practices. Establishing a proper plan that deals with risk to meet the needs of modern management practices is crucial, especially in the O\&G sector. Numerous studies have been undertaken to highlight the importance of ERM in the field of gas and oil sector. However, based on extensive literature review, it is observed that there is limited research available about the impact of ERM in enhancing business performances in the Oil \& Gas industry in Malaysia, utilizing Economic Value Added as a measuring tool.

Many organizations, like Coca Cola, DuPont, Eli Lilly, Polaroid, Pharmacia (former Monsanto), and Whirlpool adopted EVA as a measurement technique to measure performances. Most of the studies used Tobin's Q as a tool to measure firm's value (Hoyt and Liebenberg 2008; Abdelgalil 2004); and traditional measures like ROC, ROI, ROA, return on net assets RONA. EVA can eliminate the confusion and conflicts that arise when a firm uses multiple measures, such as EPS, ROI, Return on Equity (ROE), and Net Operating Profit after Tax (NOPAT) (Kudla and Arendt 2000). All of these measurements focuses are based on historical background from the past experience and overlooked any efforts to anticipate in the future. These measures do not provide any assistance for the company for their long term planning in order to secure the company's future risks. These measurements only predict the short term outcomes.

However, studies on EVA as a measurement tool for business performance is still limited. Therefore, this study intends to fill the research gap by investigating the model of Enterprise risk management to examine its effect on business performances, using EVA as a measurement tool to analyze the performances of Oil \& Gas industry of Malaysia.

Oil and gas companies face many types of risks in their operations, and therefore, identification and management of risk is very important for these companies. In order to identify and manage many types of risks, these companies use different ERM frameworks, for instance, Traditional Risk Management Framework, Committee of Sponsoring Organizations of the Treadway Commission's (COSO), ERM's model, and Arthur Andersen Business Risk Management Process (BRMP). Traditional risk management framework comprises of five components, such as identifying, analyzing, evaluating, treating, and monitoring. Committee of Sponsoring Organizations of the Treadway Commission's (COSO) ERM's model comprises of eight components, such as internal environment, objective setting, event identification, risk assessment, risk response, control activities, information and communication, and finally, monitoring. Arthur Andersen Business Risk Management Process (BRMP) comprises of seven elements, which are establish the business risk management process, assess business risks, develop business risk management strategies, design/implement risk management capabilities, 
monitor risk management performance, continuously improve risk management capabilities, and information for decision making. More recently, Lai (2012) has proposed an ERM Implementation framework that is more comprehensive in nature in defining intensity, maturity, and penetration level of ERM practices, as compared to other ERM frameworks because it covers almost all idiosyncratic risks. This newly proposed framework comprises of fourteen elements and seven areas that are ERM definition, effective communication of risk and responsibilities, philosophy of ERM, risk identification and response, compliance, risk quantification, and performance measurement. Based on its strategic nature, the proposed framework will play more significant role in identifying and managing risks, and will significantly improve business performances in terms of profitability, cost of capital, and shareholder value, which will be measured using economic value added (EVA) approach. This model is being tested for the first time in Malaysian Oil and Gas Sector to identify its applicability in identifying risks and enhancing business performances.

The benefit of Eva when compared to other tools is that EVA can be used to hold management accountable for all economic outlays, whether they appear in the income statement, balance sheet, or in the financial statements. This is possible because EVA creates one financial statement that includes all of the costs of being in business, while making the organization aware of the funds spent.

Oil and Gas production is the foundation of Malaysian economy. PETRONAS is the major Oil Company that plays a very important role for the development of oil and gas resources in Malaysia. Malaysia has the 25th largest oil reserves and the 14th largest gas reserves in the world. The O\&G sector contributes approximately $40 \%$ of the nation's total revenue (Jin et al. 2013). The Malaysian government collected direct and indirect taxes approximately RM 34.4 billion in the year 2012 (Jin et al. 2013). Most of the companies that operated in O\&G industries in Malaysia were badly affected during the 1997-1998 financial crises (Yazid and Muda 2006). This reveals that companies that operates in O\&G industries in Malaysia face various forms of risks internally or externally, political, economic, cultural, technological, operational, environmental, natural disaster, etc. The corporate scandals, frauds, and company failures are also caused due to poor risk management programs in the organization. Therefore, the stability and improvement in company performances highly depends on enterprise risk management (Sobel and Reding 2004). According to D'Arcy (2001), there are various risk management approaches, like corporate risk management, business risk management, traditional risk management, holistic risk management, strategic risk management, and integrated risk management. All of these approaches fall under the standard of Enterprise Risk Management (ERM).

Risks are not only considered as threats, but they can also be an opportunity for growth and the maximization of firm's value (Gupta 2011). Meagher and O'Neil (2000) specified that the current risk management processes are divided into parts and treat risks as disparate and individually. Nevertheless, the leading managers in most of the organizations recognized that to deal with risk by using "silo" approach is not an effective way to manage the myriad types of risks in the organization face (Walker and Shenkir 2008). Enterprise risk management implementation provides many advantages to the enterprise, like reducing risk/return profile of the company, reducing earning volatility (Lam 2003), improving management's assurance in business operations and risk monitoring, enhancing business reputation, improving enterprise-wide decision making process, boosting enterprise profitability, improving competitive advantage, and enhancing corporate performances. According to COSO, the ERM framework needs executive management commitment for its effectiveness and efficiencies of the implementation. The executives and BODs should be committed to ERM, as they are responsible to protect, improve and maximize shareholders value (Shenkir and Walker 2006).

According to Lai et al. (2011) there is a fundamental connection between ERM and improvement of shareholders' value. Based on the developed model, the implementation of Enterprise risk management framework is beneficial for the firm and the main benefits that are gained through ERM program are as follows: Decreasing risk profile, reducing earning volatility, strengthening confidence of the management in operational and monitoring business operations, generating plane governance 
actions, ornamental business status, refining clearness of organization wide resolution creation and chain of knowledge, inspiring business entrepreneurship, and exploiting firm's effectiveness. It also will help to cut down the capital cost and enhance business performances.

There are numerous factors that need to be considered when designing and planning ERM initiatives. Details of the risks, strategies and protocols should be recorded in a risk management policy for the organization. EVA emerges as the better measure of financial performance. EVA measures the impact of firm's operations on the wealth of shareholders. According to the EVA theory, earning a return greater than the cost of capital increases firms' value. Figure 1 provides information on the contents of a typical ERM \& EVA framework.

Gap in the Literature

The oil and gas companies of Malaysia can be affected by various risks, for example, health safety and environmental risk, political risk, climate risk, operational risk financial risk, etc. The main risks that appear in oil and gas companies of Malaysia are political risk, natural environmental risk, operational risk, management risk, economic risk, and regulatory risks (Zhang and Xing 2011). In order to identify the major risks in the Malaysian oil and gas industry, a checklist of risk prepared from the literature will be undertaken in this study.

\section{Conceptual Schema}

Based on the literature and our research objective, following framework is being proposed (Figure 1):

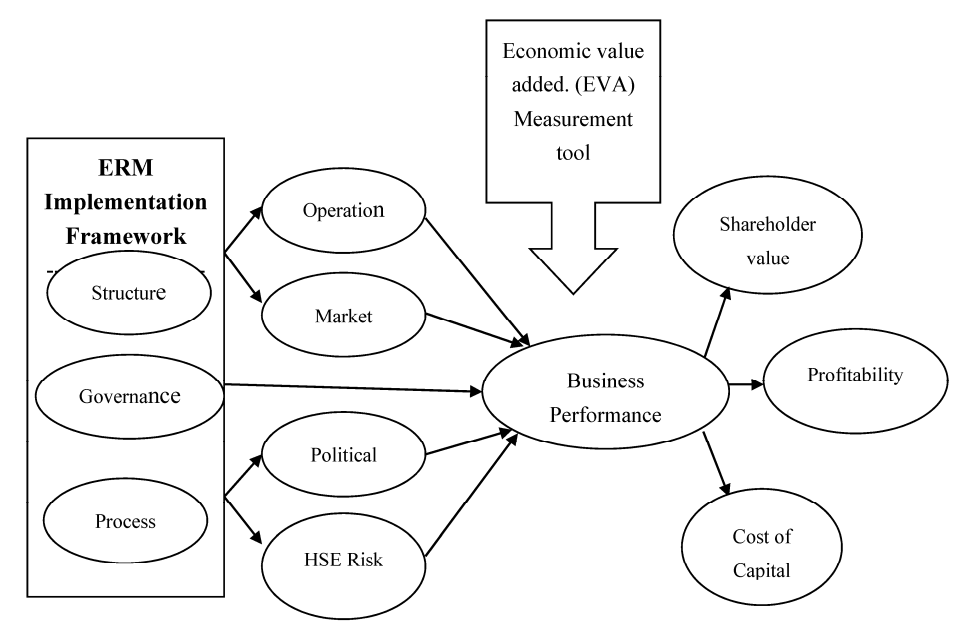

Figure 1. Conceptual model for enhancing business performance.

Hypothesis

H1. ERM Implementation framework will significantly reduce operational risk

H2. ERM Implementation framework will significantly reduce market risk

H3. ERM Implementation framework will significantly reduce political risk

H4. ERM Implementation framework will significantly reduce Health, Safety and Environmental risk

H5. Proper ERM Implementation framework will significantly improve business Performances

H6. If operational risk is low, business performance will be high

H7. If market risk is low, business performance will be high 
H8. If political risk is low, business performance will be high

H9. If HSE risk is low, business performance will be high

\section{Methodology}

The ERM framework comprises of 14 elements, and it is considered as important for the successful management of firms' risks. The ERM framework is empirically measured through 14 measurement matrices and presented to respondents and they are assessed in the form of 5-point Likert's scale. Deductive approach utilized in this study to investigate the proposed hypothesis. Therefore, this quantitative study utilizes both secondary/historical data and primary data. The primary data for the research will be gathered through questionnaires. These questionnaires were distributed in hard copies to the respondents who are particularly related to field of oil and gas in Malaysian industries. The research utilized the suggested questionnaire design by Sekaran and Bougie (2009). Sekaran and Bougie (2009) proclaimed that a decent questionnaire design needs to concentrate on three main principles. These principles are the principle of wording; a measurement in terms of categorization, coding, scales and scaling, and reliability and validity; as well as pertain to the introduction to the respondents, instructions for completion, general appearance, and length of the questionnaire (Hair et al. 2010). The main instruments used in this research are the closed-ended questionnaires since this research will be using quantitative data. This paper utilized descriptive study design in explaining, understanding and predicting the source and impact of connection between the independent and dependent variables. The survey respondents for this study were the senior officials of the companies who have had at least some experience in their enterprise risk management of the fifteen (15) selected oil \& gas companies. The position of the respondents includes general manager, senior manager, director, and risk officer in generating a different perception among the respondents for the purpose of obtaining an accurate result in this study. Purposive sampling has been employed in order to select the firms that are operating in Malaysian oil and gas sector.

\section{Data Analysis}

120 respondents were involved in the survey and the collected data was edited, coded, classified, and tabulated. Linear regression analysis is utilized in this study to break down the information. The correlation and regression coefficient gained by taking into account the quality, direction, and effect of connections that can be resolved. R, R-square, and $p$-value have been utilized to examine the outcomes. This is performed to demonstrate the relationship between ERM execution and its effect on overall revenue, monetary distress cost, tax performance, and external capital cost.

\section{Presentation of Findings}

The outcomes of reliability test reveals the value of the Cronbach's alpha scores for the each constructs composite scale, respectively, shown in Table 1. All the coefficient of Cronbach's alpha is above 0.70, which represents a satisfactory internal instrument's consistency (Malhotra et al. 2004). On the basis of these results, the other tests can be confidently executed in terms of the formulated hypotheses.

Table 1. Reliability Test.

\begin{tabular}{ccc}
\hline Constructs & Items & Cronbach's Alpha \\
\hline Operational risk & 12 & 0.702 \\
Market risk & 7 & 0.712 \\
Political risk & 7 & 0.736 \\
Health, safety and environmental risk & 6 & 0.701 \\
Business performance & 5 & 0.725 \\
\hline
\end{tabular}


Five hypotheses were established in order to analyze the impact of Enterprise Risk Management implementation on the operational risk; market risk; political risk; health, safety and environmental risk; as well as business performance. All of the five hypotheses H1, H2, H3, H4, and H5 are accepted because the generated results are proven to be positive. Table 2 summarizes the results of regression analysis for the above hypotheses.

Hypothesis H1 portray that the implementation of Enterprise Risk Management model significantly reduces the operational risk of the organization. H2 regression testing reveals that the implementation of Enterprise Risk Management will reduce market risk of the organizations. H3 regression results present that the implementation of Enterprise Risk Management has a significant positive effect in reducing the political risk of the organization. H4 demonstrated that the implementation of Enterprise Risk Management has a significant effect in terms of reducing the health, safety, and environmental risk in an organization. H5 portray that the implementation of Enterprise Risk Management significantly improve the organization's business performance.

Table 2. Enterprise risk management (ERM) Implementation-Regression Analysis Result Summary.

\begin{tabular}{ccccc}
\hline $\mathbf{H}$ & $\boldsymbol{R}$ & $\boldsymbol{R}^{\mathbf{2}}$ & Adjusted $\boldsymbol{R}^{\mathbf{2}}$ & $\boldsymbol{p}$-Value \\
\hline H1 & 0.596 & 0.356 & 0.350 & 0.000 \\
H2 & 0.538 & 0.290 & 0.283 & 0.000 \\
H3 & 0.640 & 0.410 & 0.405 & 0.000 \\
H4 & 0.397 & 0.158 & 0.151 & 0.000 \\
H5 & 0.383 & 0.137 & 0.131 & 0.000 \\
\hline
\end{tabular}

Hypothesis $\mathrm{H} 6$ demonstrated that the business performance of an organization would be high if the operational risk is low. $\mathrm{H} 7$ regression result presents the effect of lower market risk in increasing the business performance of the organization. H8 portray that the impact of political risk on high organization's business performance when it is low. H9 portray that the lower health, safety and environmental is, the higher the organization's business performances. Table 3 below summarizes the results of the regression analysis for the hypotheses.

Four hypotheses were established with the purpose of analyzing the impact on high business performance in the organization based on the lower operational risk; lower market risk; lower political risk; as well as lower health, safety, and environmental risk. These hypotheses range from H6, H7, H8, and H9. However, only H6, H7, and H9 are accepted because the generated results are proved to be having an inverse relationship while $\mathrm{H} 8$ is being rejected due to having a positive result rather than the expected result of being inversely related.

Table 3. Higher Business Performance-Regression Analysis Summary.

\begin{tabular}{ccccc}
\hline $\mathbf{H}$ & $\boldsymbol{R}$ & $\boldsymbol{R}^{\mathbf{2}}$ & Adjusted $\boldsymbol{R}^{\mathbf{2}}$ & $\boldsymbol{p}$-Value \\
\hline H6 & 0.862 & 0.743 & 0.740 & 3.001 \\
H7 & 0.789 & 0.622 & 0.619 & 0.609 \\
H8 & 0.645 & 0.417 & 0.412 & 0.004 \\
H9 & 0.763 & 0.582 & 0.578 & 0.204 \\
\hline
\end{tabular}

\section{Discussion of Findings}

The outcomes of the regression analysis for $\mathrm{H} 1$ indicates that the $p$-value is $0.000(p<0.05)$, in which refers to the existence of a significant relationship between the implementation or Enterprise Risk Management model and the operational risk of the organization. The result for $R$-value of Pearson coefficient is 0.596 for $\mathrm{H} 1$. The positive $R$-value of $\mathrm{H} 1$ portray that there is a positive relationship between the implementation of Enterprise Risk Management and operational risk of the organization that demonstrates that an increase in the practices of Enterprise Risk management will increase the 
business performance of the organization in terms of profitability, shareholder value as well as cost of capital. The value of R2 is 0.356 , indicating that $35.6 \%$ of variance of dependent variable is explained by the independent variable. Thus, hypothesis $\mathrm{H} 1$ is accepted, stating that implementation of Enterprise Risk Management gives a significant impact on the operational risk of the organization.

The outcome of the analysis on $\mathrm{H} 2$ indicates that the implementation of Enterprise Risk Management has a positive and significant relationship with its effect on the market risk of the organization. The value of the correlation coefficient specified by $\mathrm{R}$, as displayed in Table 2, is 0.538 . This value specifies that implementation of Enterprise Risk Management provide a significant impact on the market risk of an organization. The value of $R^{2}$ obtained from the analysis performed on $\mathrm{H} 2$ is 0.290 , in which states that $29 \%$ variance in terms of market risk can be predicted through the usage of Enterprise Risk Management. The $p$-value, on the other hand, shows the significance of the connection between the two variables as having the value of 0.000 , in which aligned with $p<0.05$ that indicates a significant linear association between the implementation or Enterprise Risk Management and its impact on the organization's market risk. Hence forward, hypothesis H2 is accepted that attesting implementation of Enterprise Risk Management have a significant effect on the market risk of an organization.

The result of the regression test on hypothesis $\mathrm{H} 3$ indicates that the implementation of Enterprise Risk Management has a significantly positive relationship to the political risk of the organization. The value of the correlation coefficient for H3 portrayed by $R$ is 0.640 , while the value of $R^{2}$ is 0.410. The results indicate that $41 \%$ variance in market risk can actually be indicated through the implementation of Enterprise Risk Management, while ascertaining that the implementation of Enterprise Risk Management do give a significant impact on the political risk of an organization. The $p$-value obtained from the analysis is $0.000(p<0.05)$. This value indicates the presence of a significant linear association between the implementation of Enterprise Risk Management and its impact on the political risk of the organization. Hence, hypothesis H3 is accepted with the results demonstrating that the implementation of Enterprise Risk Management minimizes the political risk in the organization.

Hypothesis H4 stated that the implementation of Enterprise Risk Management has a significant impact on the health, safety, and environmental risk of the organization. The result displays that there is a significant relationship between the implementation of Enterprise Risk Management and health, safety, and environmental risk to be positive and significant. This is proven by the value of the correlation coefficient, $R(0.397)$, which is obtained from the regression analysis performed. The value of $R^{2}$ on the other hand is 0.158 , in which refers to the fact that $15.8 \%$ variance in health, safety, and environmental risk can be predicted through the implementation of Enterprise Risk Management. The $p$-value of the regression analysis for $\mathrm{H} 4$ is $0.000(p<0.05)$. The value indicates that a significant linear association between the implementation of Enterprise Risk Management and its impact on health, safety, and environmental risk of the organization do exist. Hence, hypothesis $\mathrm{H} 4$ is accepted and states that ERM implementation gives a significant impact on the organization's health, safety, and environmental risk. However, the value of Pearson coefficient, which is 0.397 , is quite low. However, $R$-value is 0.397 , with a positive sign in which it indicates that the existence of a positive relationship between both independent and dependent variables.

Hypothesis H5, on the other hand, stated that the implementation of Enterprise Risk Management has a significant impact on the business performance of the organization. H5 also display the results that indicate that there is a positive and significant relationship between the implementation of Enterprise Risk Management and business performance. The evidence is revealed by the value of the correlation coefficient, $R(0.383)$ obtained from the result of regression analysis. The value of $R^{2}$ for $\mathrm{H} 5$ is 0.137 , in which refers to the fact that $13.7 \%$ of business performance's variance can be indicated with the use of the implementation of Enterprise Risk Management. The $p$-value of the regression analysis for $\mathrm{H} 5$ is $0.000(p<0.05)$. This value states the existence of a significant linear association between the implementation of Enterprise Risk Management and its impact on business 
performance of the organization. Hence, hypothesis $\mathrm{H} 5$ is accepted and at the same time proving that ERM implementation gives a significant impact on the organization's business performance. However, the value of Pearson coefficient, which is 0.383 , is very low. This refers to the fact that the effect achieved through the implementation of Enterprise Risk Management on the business performance of the organization is quite weak, although the $R$-value is 0.383 with positive sign, in which indicates the existence of a positive relationship between both independent and dependent variables.

As shown in Table 4, the results for five of the hypotheses in terms of the linear regression analysis showed that the Pearson correlation and regression co-efficient of ERM implementation are significant at $p<0.05$, in which indicates that the implementation of Enterprise Risk Management have a significant positive linear association with operational risk, market risk, political risk, business performance, as well as health, safety, and environmental risk. Thus, all five hypotheses testing the impact of the implementation of Enterprise Risk Management are accepted.

As shown in Table 5, results for four of the hypotheses in terms of the linear regression analysis showed that the Pearson correlation and regression co-efficient of higher business performance are all in the positive range, in which a significant positive linear association with operational risk, market risk, political risk, as well as health, safety, and environmental risk. Thus, all four hypotheses testing the impact of all the variables on the business performance are rejected since the expected result are supposed to be inverse relationship.

Table 4. ERM Implementation-Hypothesis Testing Summary.

\begin{tabular}{cccccc}
\hline $\mathbf{H}$ & $\boldsymbol{R}$ & $\boldsymbol{R}^{\mathbf{2}}$ & Adjusted $\boldsymbol{R}^{\mathbf{2}}$ & $\boldsymbol{p}$-Value & Status \\
\hline H1 & 0.596 & 0.356 & 0.350 & 0.000 & Accepted \\
H2 & 0.538 & 0.290 & 0.283 & 0.000 & Accepted \\
H3 & 0.640 & 0.410 & 0.405 & 0.000 & Accepted \\
H4 & 0.397 & 0.158 & 0.151 & 0.000 & Accepted \\
H5 & 0.383 & 0.137 & 0.131 & 0.000 & Accepted \\
\hline
\end{tabular}

Table 5. Higher Business Performance-Hypothesis Testing Summary.

\begin{tabular}{cccccc}
\hline $\mathbf{H}$ & $\boldsymbol{R}$ & $\boldsymbol{R}^{\mathbf{2}}$ & Adjusted $\boldsymbol{R}^{\mathbf{2}}$ & $\boldsymbol{p}$-Value & Status \\
\hline H6 & 0.862 & 0.743 & 0.740 & 3.001 & Rejected \\
H7 & 0.789 & 0.622 & 0.619 & 0.609 & Rejected \\
H8 & 0.645 & 0.417 & 0.412 & 0.004 & Rejected \\
H9 & 0.763 & 0.582 & 0.578 & 0.204 & Rejected \\
\hline
\end{tabular}

Hypothesis H6, on the other hand, stated that the higher business performance in the organization can be achieved if the operational risk is lower. This hypothesis will definitely refer to an inverse relationship between the two variables. From the result of the regression analysis, the value of the correlation coefficient for H6 portrayed by $R$ is 0.862 , while the value of $R^{2}$ is 0.743 . The reason behind these results is that $74.3 \%$ variance in business performance can be indicated through the operational risk, while proving that the operational risk do give a significant impact on the business performance of an organization. The $p$-value obtained from the analysis is $3.001(p>0.05)$. This value indicates a very weak evidence of a significant linear association between the business performance and operational risk of the organization. Apart from that, the $p$-value obtained from the result is a positive value, whereas it is expected to be a negative value. Thus, hypothesis H6 is rejected with the results proving that the higher business performance will only be achieved with higher operational risk in the organization.

Hypothesis $\mathrm{H7}$ stated that low market risk has a significant impact on higher business performance of the organization. The results indicate the connection between the implementation of Enterprise Risk Management and health, safety, and environmental risk to be inversely proportional and significant. The result had proven otherwise, whereby the $p$-value of the regression analysis for $\mathrm{H} 7$ is $0.6(p>0.05)$, 
in which indicates that a weak evidence of significant positive linear association between the market risk and its impact on the business performance. The value of the correlation coefficient, $R$ is obtained from the regression analysis performed is 0.789 . The value of $R^{2}$ on the other hand is 0.622 , in which refers to the fact that $66.2 \%$ variance in business performance of the organization can be predicted through market risk. Hence, hypothesis $\mathrm{H} 7$ is also rejected and proving that higher business performance in the organization can be achieved if the market risk is high.

Hypothesis $\mathrm{H} 8$ indicates that the political risk has an inverse relationship with its effect on the business performance of the organization. The value of the correlation coefficient specified by $R$, as displayed is 0.645 . This value specifies that political risk do give a significant impact on the business performance of an organization. The value of $R^{2}$ obtained from the analysis performed on $\mathrm{H} 8$ is 0.417 in which it states that $41.7 \%$ variance in terms of business performance can be predicted through the level of political risk. The $p$-value, on the other hand, shows the significance of the relationship between the two variables with the value of 0.004 , in which aligned with $p<0.05$ that indicates a significant linear association between political risk and its impact on the organization's business performance. However, hypothesis $\mathrm{H} 2$ is rejected since the result is expected to be achieved from the analysis does not refer to the fact that higher business performance can be achieved with low political risk-an inverse relationship rather than positive.

H9 indicates that the health, safety, and environmental risk needed to increase the business performance of the organization. The value of the correlation coefficient specified is 0.763 . This value specifies that health, safety, and environmental risk do give a significant impact on the business performance of an organization. The value of $R^{2}$ that is obtained from the analysis performed on $\mathrm{H} 9$ is 0.582 , in which states that $58.2 \%$ of business performance's variance can be indicated by the level of health, safety, and environmental risk. The $p$-value of $\mathrm{H} 9$ analysis on the other hand, shows the significance of the relationship between the two variables of possessing the value of 0.204 , in which aligned with $p>0.05$, which indicates a weak evidence of a significant linear association between health, safety, and environmental risk, as well as its impact on the organization's business performance. Therefore, hypothesis H9 will not only be rejected due to this, but also because of the fact that the result from the analysis was expected to be referring to the fact that higher business performance is achievable when the level of health, safety, and environmental risk is low, thus indicating an inverse relationship rather than positive.

\section{Conclusions and Recommendations}

The proposed research contributes to the knowledge of ERM implementation in enhancing business performance in the oil and gas companies in Malaysia. This contribution will be substantial since understanding the outcomes of ERM implementation in oil and gas companies in Malaysia will help to enhance the business performances.

In light of the findings in the Enterprise Risk Management practices in Malaysian oil and gas companies, some limitations have been revealed through the execution of this research. Therefore, a framework is proposed in order to guide the oil and gas companies in Malaysia in terms of risk management reporting as well as disclosure. The proposed framework is adapted from the components of risk management framework by Committee of Sponsoring Organizations of the Treadway Commission (COSO). The companies are proposed to have an in-house department/committee for Enterprise Risk Management in their organizations to identify risk factors and objectives of Enterprise Risk Management. Additionally, the influence of risks must be identified, as this information is extremely useful to the shareholders in order to consider the likelihood of the prospect for their investments in oil and gas companies in Malaysia.

Enterprise Risk Management improves business performance in terms of the cost of capital, profitability, as well as value of shareholder, and it is considered as a strategic instrument for an organization to be successful. This study employed Economic Value Added analysis based on apparent metric of measurement in measuring business performance, as well as Enterprise Risk Management 
as a dependent variable. The results of the regression analysis conducted for in this study suggested that a significant and positive relationship between Enterprise Risk Management with operational risk; market risk; political risk; health, safety and environmental risk; and, also business performance. This study also proved that the inverse relationship of the operational risk, market risk, political risk as well as health, safety and environmental risk with the business performance of the organization does not exist. Thus, the results of this study sustenance the argument of the specialists in the field of Enterprise Risk Management, for instance, Lai and Samad (2010), Mensah et al. (2014), Lai (2014), Samad et al. (2010), Currivan (2003), as well as Malhotra and Birks (2007).

\section{Recommendations $\mathcal{E}$ Limitations}

Since this study had already presented a framework of Enterprise Risk Management performance measurement based on Economic Value Added analysis, there are some ideas that are suggested for future developments. Future research could focus in analyzing the effect of the implementation dimension in a quantitative and qualitative manner in adopting the Enterprise Risk Management model with respect to the factors on the value of organization under the Economic Value Added analytical model. The framework that is proposed in this study only consists of the following elements: business performance; operational risk; health, safety and environmental risk; political risk; and, market risk. These are the minimum rations that the oil and gas companies in Malaysia should be complying with because these represent the best practices of Enterprise Risk Management. In terms of future researches, more or different elements should be used so that this topic can be further explored on how does Enterprise Risk Management in terms of Economic Value Added analysis can provide a positive significant impact on the organization. Apart from that, offering an additional disclosure is also encouraged since this is highly possible to add more value for the shareholders, as well as the investors, and not to mention a few other users of annual reports in order to make their decision.

Author Contributions: All authors contributed equally to this work.

Conflicts of Interest: The authors declare no conflicts of interest.

\section{References}

Abdelgalil, Eisa. 2004. Measuring Manufacturing Performance: A Literature Review. Dubai: Dubai Chamber of Commerce \& Industry.

Beasley, Mark S., Richard Clune, and Dana R. Hermanson. 2006. The impact of enterprise risk management on the internal audit function. In Strategic Finance. Kennesaw: Digital Commons, vol. 1, pp. 1-26.

Black, Andrew. 1998. In Search of Shareholder Value: Managing the Drivers of Performance, 1st ed. London: Pitman.

Currivan, Douglas. 2003. Sampling Frame. In The Sage Encyclopedia of Social Science Research Methods. Thousand Oaks: Sage.

D’Arcy, Stephen P. 2001. Enterprise Risk Management. Journal of Risk Management of Korea 12: 207-28.

Drew, Stephen A., Patricia C. Kelley, and Terry Kendrick. 2005. CLASS: Five Elements of Corporate Governance to Manage Strategic Risk. Amsterdam: Elsevier Inc.

Financial Express. 1998. Financial Express, Aviation: Malaysia Airlines May Dividend into the Red. Kuala Lumpur: Financial Express.

Gupta, Pankaj Kumar. 2011. Risk management in Indian companies: EWRM concerns and issues. The Journal of Risk Finance 12: 121-39. [CrossRef]

Hair, Joseph F., Jr., William C. Black, Barry J. Babin, and Rolph E. Anderson. 2010. Multivariate Data Analysis, 7th ed. Upper Saddle River: Prentice Hall.

Hoyt, Robert E., and Andre P. Liebenberg. 2008. The Value of Enterprise Risk Management: Evidence from the U.S. Insurance Industry. Available online: http:/ / www.risknet.de/typo3conf/ext/bx_elibrary/ elibrarydownload.php?\&downloaddata=537 (accessed on 11 January 2018).

Jalal-Karim, Akram. 2013. Leveraging enterprise risk management (ERM) for boosting competitive business advantages in Bahrain. World Journal of Entrepreneurship, Management and Sustainable Development 9: 65-75. [CrossRef] 
Jin, Kar Ong, Teh Chi-Chang, and Eugene Lee. 2013. The Malaysian Oil \& Gas Sector-Scoping Report. Kuala Lumpur: Malaysia Research for Social Advancement, Malaysian Oil \& Gas Sector.

Kudla, Ronald J., and David A. Arendt. 2000. Making EVA work. Corporate Finance 20: 98-103.

Lai, Fong-Woon. 2012. A review of Enterprise risk management practices among Malaysian public listed companies. World Academy of Science, Engineering and Technology 6: 2030-36.

Lai, Fong-Woon. 2014. A Conceptual Framework for Enterprise Risk Management performance measure through Economic Value Added. Global Business and Management Research 7: 1.

Lai, Fong-Woon, Noor Azlinna Azizan, and M. Fazilah Abdul Samad. 2011. A Strategic Framework for Value Enhancing Enterprise Risk Management. Journal of Global Business and Economics 2: 23-48.

Lai, Fong-Woon, and Fazilah A. Samad. 2010. Enterprise Risk Management Framework and the Empirical Determinants of Its Implementation. Risk 6: 8.

Lam, James. 2003. Enterprise Risk Management: From Incentive to Controls. Hoboken: John Wiley.

Malhotra, Naresh K., and David F. Birks. 2007. Marketing Research: An Applied Approach, 3rd ed. London: Pearson Education.

Malhotra, Naresh K., John Hall, Mike Shaw, and Peter A. Oppenheim. 2004. Essentials of Marketing Research: An Applied Orientation. Australia: Pearson Education.

Meagher, David, and Garett O'Neil. 2000. Enterprise wide: risk management. Accountancy Ireland 32: 10.

Mensah, Lord, Margret Crabbe, James Antwi, and Owusu-Antwi George. 2014. Determinants of Bank Performance in Ghana, the Economic Value Added (EVA) Approach. International Journal of Economics and Finance 7: 203.

Nguyen, Van Thuyet, Stephen O. Ogunlana, and Prasanta Kumar Dey. 2007. Risk management in oil and gas construction projects in Vietnam. International Journal of Energy Sector Management 1: 175-94.

Nocco, Brian W., and René M. Stulz. 2006. Enterprise risk management: Theory and practice. Journal of Applied Corporate Finance 18: 8-20. [CrossRef]

Othman, Radiah, and Rashid Ameer. 2008. Market Risk Disclosure: Evidence from Malaysian Listed Firms. Journal of Financial Regulation and Compliance 13: 57-69. [CrossRef]

Richard, Pierre J., Timothy M. Devinney, George S. Yip, and Gerry Johnson. 2009. Measuring Organizational Performance: Towards Methodological Best Practice. Journal of Management 35: 718-804. [CrossRef]

Samad, M. Fazilah Abdul, Noor Azlinna Azizan, and Fong-Woon Lai. 2010. A Conceptual Framework for Value Enhancing Enterprise. Risk Management 2: 23-47.

Sekaran, Uma, and Roger Bougie. 2009. Research Methods for Business: A Skill Building Approach, 5th ed. New York: John Wiley and Sons Ltd.

Shenkir, William G., and Paul L. Walker. 2006. Enterprise Risk Management and the strategy risk focused organization. Cost Management 20: 1-43.

Sobel, Paul J., and Kurt F. Reding. 2004. Aligning corporate governance with enterprise risk management. Management Accounting Quarterly 5: 1-9.

Stewart, G. Bennett. 1990. The Quest for Value. New York: Harper Collins Publishers.

Walker, Paul L., and William G. Shenkir. 2008. Implementing enterprise risk management. Journal of Accountancy 205: 31-33.

Yazid, Ahmad Shukri. 2001. Perceptions and Practices of Financial Risk Management in Malaysia. Ph.D. thesis, Glasgow Caledonian University (GCU), Glasgow, UK.

Yazid, Ahmad Shukri, and Mohd Shaladdin Muda. 2006. The Role of Foreign Exchange Risk Management in Malaysia. Irish Journal of Management 26: 45.

Zhang, Yanting, and Liyun Xing. 2011. Research on Risk Management of Petroleum Operations. Energy Procedia 5: 2330-34.

(C) 2018 by the authors. Licensee MDPI, Basel, Switzerland. This article is an open access article distributed under the terms and conditions of the Creative Commons Attribution (CC BY) license (http://creativecommons.org/licenses/by/4.0/). 